\title{
PENGARUH BRAND AWARENESS, BRAND IMAGE, DAN BRAND TRUST TERHADAP KEPUTUSAN PEMBELIAN PADA PRODUK POCARI SWEAT DI JAKARTA
}

\author{
Yusi Intan Junia \\ Program Studi Magister Manajemen Universitas Tarumanagara \\ juniayusiintan96@gmail.com
}

Masuk : 16-07-2020, revisi : 27-07-2020 diterima untuk diterbitkan : 28-07-2020

\begin{abstract}
The purpose of this study is to look at the factors that influence the decision of purchasing products in Indonesia. The researcher uses the Pocari Sweat brand as a model for the use of body fluids. This study uses a questionnaire method. Data from 231 respondents who used Pocari Sweat products were processed using SPSS version 24.0. The result is brand awareness, and brand trust towards positive product purchasing decisions. The partially perceived quality has no positive effect. Brand awareness, perceived quality and brand trust. This research provides input to academics and beverage beverage companies along with ionic drinks in Indonesia.
\end{abstract}

Keywords: Purchase Decision, Brand Awareness, Brand Image, Brand Trust

\begin{abstract}
Abstrak: Tujuan penelitian ini adalah untuk melihat faktor yang mempengaruhi terhadap kepuasan pembelian produk pada produk minuman ion di Indonesia. Peneliti menggunakan merk Pocari Sweat sebagai model pengganti cairan tubuh. Penelitian ini menggunakan metode kuesioner. Data dari 231 responden yang mengkonsumsi produk Pocari Sweat diolah menggunakan SPSS versi 24.0. Hasilnya adalah brand awareness, dan brand trust secara parsial mempunyai pengaruh positif terhadap keputusan pembelian terhadap produk. Perceived quality secara parsial tidak mempunyai pengaruh positif terhadap keputusan pembelian produk. Brand awareness, perceived quality dan brand trust secara simultan mempunyai pengaruh positif terhadap keputusn pembelian. Penelitian ini memberikan masukan kepada akademisi dan perusahaan minuman kemasan sekaligus minuman ion bagaimana meningkatkan keputusan pembelian produk minuman kemasan ion di Indonesia.
\end{abstract}

Kata Kunci: Keputusan Pembelian, Brand Awareness, Brand Image, Brand Trust

\section{LATAR BELAKANG}

Saat ini perusahaan terus berusaha memfokuskan aktivitas untuk menciptakan value bagi customer-nya. Keputusan pembelian adalah tindakan dari konsumen untuk mau membeli atau tidak terhadap produk (Kotler, 2002). Dari berbagai faktor yang mempengaruhi konsumen dalam melakukan pembelian suatu produk atau jasa, biasanya konsumen selalu mempertimbangkan kualitas, harga dan produk sudah yang sudah terkenal oleh masyarakat sebelum konsumen memutuskan untuk membeli, biasanya konsumen melalui beberapa tahap terlebih dahulu yaitu, (1) pengenalan masalah, (2) pencarian informasi, (3) evalusi alternatif, (4) keputusan membeli atau tidak, (5) perilaku pasca pembelian.

Brand adalah salah satu aset intangible perusahaan yang paling berharga dan merupakan suatu tugas bagi tim pemasaran untuk dapat mengelola nilainya dengan benar (Kotler \& Keller, 2016). Dlacic \& Kezman (2014) melakukan penelitian untuk mengetahui pengaruh elemen brand equity (brand awareness dan perceived quality) dan brand trust pada produk farmasi (obat bebas) di Krosia. Pada penelitian ini, peneliti akan merujuk ke penelitian Dlacic \& Kezman (2014) yang meneliti brand awareness, perceived quality dan brand trust pada produk farmasi di Indonesia. 
Saat ini terdapat sejumlah pemain untuk kategori produk minuman isotonik. Berdasarkan data dari Balai Pengawasan Obat dan Makanan (BPOM), terdapat 83 produk minuman isotonik yang terdaftar di BPOM dengan sekitar 31 merek.

Pocari Sweat merupakan minuman kesehatan yang diproduksi oleh perusahaan farmasi Otsuka (Flipina) Pharmaceutical Incorporated (OPPI). Pocari Sweat pertama diperkenalkan di Jepang pada tahun 1980 dan sejak itu telah menjadi favorit bagi konsumen Jepang. Minuman kesehatan ini merupakan minuman isotonik yang dapat membantu mengganti cairan denelektrolit yang hilang melalui keluarnya keringat. Hari ini, Pocari Sweat dinikmati oleh konsumen di 14 negara di seluruh dunia, termasuk Korea, Indonesia, Malaysia, Hong Kong, Cina, Thailand dan Uni Emirat Arab. Pocari Sweat mulai masuk pasar Indonesia pada tahun 1989 dan dikembangkan oleh PT Amerta Indah Otsuka (AIO). Pada tahun 1991, pabrik Pocari Sweat didirikan di Lawang (Malang, Jawa Timur) untuk melayani pasar Indonesia. Kemudian pada bulan Januari 2004, terjadi pemindahan pabrik ke Sukabumi, Jawa Barat hingga kini.

\section{TUJUAN PENELITIAN}

1. Untuk mengetahui besarnya pengaruh brand awareness secara pasrsial terhadap keputusan pembelian produk Pocari Sweat.

2. Untuk mengetahui besarnya pengaruh brand image secara parsial terhadap keputusan pembelian produk Pocari Sweat.

3. Untuk mengetahui besarnya pengaruh brand awareness, perceived image dan brand trust secara bersama-sama terhadap keputusan pembelian produk Pocari Sweat.

\section{PENELITIAN TERDAHULU}

Tony Sitinjak dan Tumpal J.R.S (2005) dalam "Pengaruh Citra Merek dan Sikap Merek terhadap Ekuitas Merek, Brand Associatons (Asosiasi Merek), Brand Image (Citra Merek), Brand Attitude (Sikap Merek) dan Brand Equity (Ekuitas Merek) menunjukkan bahwa citra merek berpengaruh langsung terhadap ekuitas merek. Total sikap merek terhadap ekuitas merek adalah signifikan. Signifikan dicapai karena hubungan positif yang tidak langsung dengan melalui citra.

Dlacic \& Kezman (2014) dalam "Brand Awarenes, Perceived Quality, dan Brand Trust" membahas variabel dependen Customer Loyalty pada jenis industri produk farmasi (Obat Pereda Sakit) di Krosia dengan jumlah responden 275. Hasil dari penelitian tersebut menunjukkan bahwa Brand Awareness dan Perceived Quality berpengaruh positif terhadap Customer Loyalty, tetapi Brand Trust tidak berpengaruh positif terhadap Customer Loyalty.

Amelia (2019) dalam "Pengaruh Brand Awareness dan Kepuasan Pelanggan terhadap Loyalitas Pelanggan (Studi pada Pelanggan Produk Spring Bed Merek Kangaroo di Toko Prioritas, Pekanbaru)" menemukan adanya pengaruh yang signifikan dan positif dari pembelanjaan terhadap pelanggan dalam dimensi ekuitas merek Spring bed Kangaroo. Selain itu ditemukan pengaruh yang signifikan terhadap loyalitas pelanggan kualitas persepsian dan citra merek.

\section{KERANGKA PEMIKIRAN}

Dalam penelitian ini ingin mengetahui setiap variabel independen, yaitu Brand Awareness (X1), Brand Image (X2), Brand Trust (X3) terhadap variabel dependen Keputusan Pembelian produk (Y).

1. Brand Awareness (X1) terhadap Keputusan Pembelian Produk (Y)

2. Brand Image (X2) terhadap Keputusan Pemebelian produk (Y)

3. Brand Trust (X3) terhadap Keputusan Pembelian Produk (Y)

Dengan hubungan antara variabel X1 terhadap Y, variabel X2 terhadap Y dan Variabel $\mathrm{X} 3$ terhadap Y seperti diatas, maka dapat disusun kerangka penelitian 


\section{METODOLOGI PENELITIAN}

Metode penelitian yang digunakan oleh peneliti adalah metode deskriptif. Metode deskriptif adalah metode yang menggambarkan, mengunpulkan, menyajikan serta menginterpretasikan data sehingga didapat gambaran yang deskriptif dan sistematis (Sekaran, 2009).

Kuesioner disebar bulan Akhir Bulan Mei-Juni 2020. Kuesioner tersebut diberikan kepada masyarakat yang pernah mengkonsumsi produk Pocari Sweat di Jakarta. Hal ini dilakukan sebagai langkah awal untuk melakukan pengujian validitas dan reliabilitas.

Teknik pengambilan sampel yang digunakan adalah convience sampling dimana peneliti menyebarkan kuesioner dari populasi tertentu yang mudah dijangkau. Responden yang dipilih harus mempunyai karakteristik tertentu yaitu customer produk Pocari Sweat di Jakarta.

Data yang diambil adalah dari sampel yang mewakili populasi. Ukuran sampel menurut Bahri \& Zamzam (2015) adalah jumlah indikator dikalikan dengan 5. Karena penelitian ini menggunakan 18 indikator, maka ukuran minimal sampel dalam penelitian ini adalah 90 orang, yang kemudian dibulatkan menjadi 100 orang. Sampel yang diambil harus mempunyai karakteristik tertentu, yaitu customer produk Pocari Sweat di Jakarta.

Penelitian ini bersifat kuantitatif. Berdasarkan cara memperoleh data, penelitian ini menghasilkan data primer. Adapun data primer yang didapatkan peneliti berupa data kuesioner yang dikumpulkan dari costumer produk Pocari Sweat.

Teknik pengumpulan data yang dilakukan oleh peneliti dalam penelitian ini adalah peneliti memberikan kuesioner kepada masyarakat di sekitar daerah Jakarta yang sudah pernah mengkonsumsi Pocari Sweat.

Variabel penelitian adalah variabel yang mempengaruhi variabel dependen, baik pengaruh positif maupun negatif. Variabel independen dalam penelitian ini adalah Brand Awareness (X1), Brand Image (X2), dan Brand Trust (X3).

\section{HASIL \& KESIMPULAN}

Berdasarkan hasil analisis dapat disimpulkan sebagai berikut:

1. Variabel Brand Awareness mempunyai nilai T hitung (2.664) yang lebih besar dari $\mathrm{T}$ tabel (1.980) dan nilai $\mathrm{p}<0.05$. Dengan demikian, variabel Brand Awareness secara parsial memiliki pengaruh positif dan signifikan terhadap keputusan pembelian produk (H1 diterima)

2. Variabel Perceived Quality mempunyai nilai T hitung (0.512) yang lebih kecil dari $\mathrm{T}$ tabel (1.980) dan nilai $\mathrm{p}>0.05$. Dengan demikian variabel Perceived Quality secara parsial tidak memiliki pengaruh signifikan terhadap kepuusan pembelian (H2 ditolak)

3. Variabel Brand Trust mempunyai nilai T hitung (8.618) yang lebih besar dari T tabel (1.980) dan nilai $\mathrm{p}<0.05$. Dengan demikian, variabel Brand Trust secara parsial memiliki pengaruh positif dan signifikan terhadap keputusan pembelian (H3 diterima)

4. Variabel Brand Awareness, Perceived Quality dan Brand Trust mempunyai nilai F < 0.05 (nilai F = 0.000). Dengan demikian, variabel Brand Awareness, Perceived Quality dan Brand Trust secara bersama-sama memiliki pengaruh positif dan signifikan terhadap keputusan pembelian produk (H4 diterima).

Peneliti menyarankan kepada PT Amerta Indah Otsuka (AIO) untuk memperhatikan dan berfokus pada kegiatan untuk meningkatkan Brand Awareness dan Brand Trust Pocari Sweat karena kedua variabel tersebut berpengaruh langsung terhadap keputusan pembelian produk. Brand Trust memiliki pengaruh lebih besar terhadap keputusan pembelian daripada Brand Awareness. Hal ini terlihat dari koefesien regresi Brand Trust (X3) lebih besar daripada koefesien regresi Brand Awareness (X1).

Hasil tanggapan responden menunjukan bahwa tingkat Brand Awareness customer Pocari Sweat sudah tinggi (nilai rata-rata sebesar 4.218). Indikator "Saya dapat dengan mudah 
mengingat merek Pocari Sweat" memiliki nilai rata-rata paling tinggi dibandingkan indikator lainnya (nilai rata-rata sebesar 4.47).

Saran kepada PT Amerta Indah Otsuka (AIO) untuk meningkatkan Brand Awareness yang bisa dilihat dari tanggapan hasil responden, yaitu memperbaiki tampilan kemasan produk dan logo produk Pocari Sweat. Kedua indikator ini mempunyai nilai rata-rata yang relatif lebih rendah dibandingkan indikator lain (nilai rata-rata untuk indikator "Saya suka dengan tampilan produk Pocari Sweat" sebesar 3.95 dan nilai rata-rata untuk indikator "Saya suka dengan logo produk Pocari Sweat sebesar 3.83.

\section{DAFTAR PUSTAKA}

Aker J., Beck, M., Travis, S. \& Harris. (2014). Consumer navigation and selection behaviors for OTC product in a retail setting. Concentrics Research.

Bahri, S., \& Zamza, F. (2015). Metode Penelitian Kuantitatif Berbasis SEM-Amos. Yogyakarta: Deepublish

Burn, A. \& Bush, R. (2014). Marketing Reach ( $7^{\text {th }}$ ed). USA: Pearson

Dlacic, J. \& Kezman, E. (2014). Exploring relationship between brand equity and costumer loyalty on pharmaceutical market. 16(2) 121-131.

Erida \& Shinta, S. (2015). Pengaruh ekuitas merk terhadap loyalitas konsumen smartphone samsung berbasis android. Digest Marketing, 1(1), 58-64.

Juliandi, A., Irfan \& Zulkarnain, F. (2014). Metodologi Penelitian Bisnis: Konsep dan Aplikasi. Medan: UMSU Press.

Keller, K. L. (2013). Strategic Brand Management. United Kingdom: Pearson

Kotler, P. \& Keller, K. L. (2016). Marketing Mamagement. USA: Pearson Education Inc.

Oliver, R. L. (1999). Whence consumer loyalty. Journal of Marketing, 63(2), 33-44

Priyastama, R. (2017). Buku Sakti Kuasai SPSS: Pengolahan Data \& Analisis Data. Yogyakarta: Start Up.

Rahmatina, M., Saryadi \& Listyorini, S. (2016). Pengaruh brand image, perceived quality terhadap loyalitas pelanggan melalui kepuasan konsumen sebagai variabel intervening. Jurnal Ilmu Administrasi Bisnis, 5(1).

Sekaran, U. (2009). Research Method for Business. Jakarta: Salemba Empat.

Supranto. (2010). Analisis Multivariat: Arti \& Interpretasi. Jakarta: Rineka Cipta. 